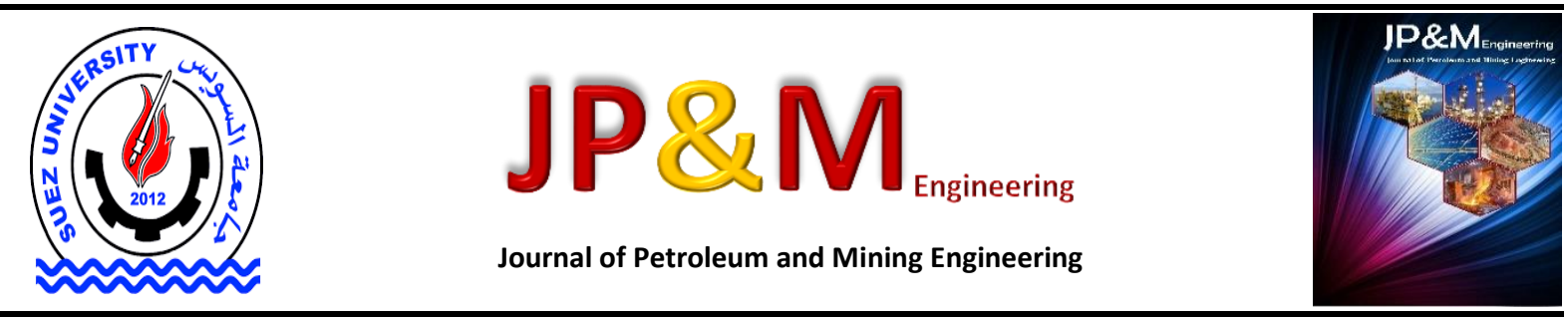

\title{
A Superstructure Model for Indirect Inter-Plant Water Integration for Selecting the Optimum Single-Pass and Partitioning Regenerators
}

\author{
Shehata, W. M.*, Gad, F. K. \\ Department of Petroleum Refining and Petrochemical Engineering, Faculty of Petroleum and Mining Engineering-Suez University, Suez- \\ Egypt \\ *Corresponding author: walaa.sliman@suezuniv.edu.eg
}

\begin{abstract}
Article Info
Received 3 Aug. 2020

Revised 3 Nov. 2020

Accepted 10 Dec. 2020
\end{abstract}

\section{Keywords}

water network; single-pass regeneration; partitioning regeneration; MINLP

\begin{abstract}
Water scarcity and stricter regulations on industrial effluents have led to a different view of water use. Water recycling / reuse is the most common technology used to reduce water and wastewater. The integration of multiple industrial plants, known as the inter-plant integration, has gained a great attention in recent years. Inter- plant water integration is a new technology that can be applied to water integration. This technology can be used to reduce water consumption and water discharge of various water networks in eco-industrial plants. This can be achieved directly or indirectly through the use of regenerators. In this work, a superstructure model for the indirect inter-plant water integration is proposed, for selecting the optimum regenerators of single pass and partitioning regenerators. Mixed integer non-linear program (MINLP) was formulated and solved for optimum solution. A literature case study is used to verify the effectiveness of the proposed model. The results showed that there was a significant decrease in the fresh and the discharge water of the integrated plants.
\end{abstract}

\section{Introduction}

Water is an important utility in industry. The delivered wastewater from different industrial processes may contain various hazardous pollutants. Water integration is very important for minimizing freshwater usage as well as wastewater discharge. Most of the established methodologies for wastewater minimization have focused on water integration in a specified plant. Recently, considerable attention has been dedicated to the synthesis of water networks taking into consideration the integration through several industrial plants.

Chew et al. [1] introduced a centralized hub topology, which took into consideration water collection, treatment and re-distribution among neighbour plants in an industrial zone. Alnouri et al. [2] have optimized inter- plant water networks having recycling techniques with genetic algorithms, while Garcia and You [3] have focused on optimizing water requirement for process networks of biofuel products, using multi-objective mixed integer nonlinear program (MINLP). Additionally, Liu et al. [4] have developed a plant-based model aimed to define the best water allocation of inter-plants in industrial parks. Their work aimed to reduce redundant solutions of networks superstructure at the building stage. Moreover, Alnouri et al. [5] proposed multiple approaches to optimize reuse networks and wastewater regeneration in industrial parks effectively. Their work aimed to identify the optimal reuse strategies and wastewater treatment. Multiperiod management of water networks have been studied by Liu et al. [6], taking into consideration the predictable variations for industrial parks. On the 
other hand, Li [7] has introduced a pinch-based relative outlet concentration to evaluate the processes potential, such as source streams of the internal water main, to get the initial water-using network. Recently, Aziz and Hashim [8] have utilized the symbiosis concept to optimize water-energy nexus in industrial sites. Their concept has demonstrated the viable inter-plant integration of power, heat, as well as water.

Although many researchers have worked on interplant water networks in recent years for wastewater minimization, there is no work till now handled the regenerative water networks using different types of available regenerators. In the literature; some work discuss the inter-plant water systems with single pass regeneration systems $[1,9-11]$ and others discuss the water systems with partitioning regeneration system $[11,12]$.

In this work, single-pass and partitioning regenerators are used. A single-pass regenerator has single inlet and outlet, while the partitioning regenerator has two outlet streams, i.e. product and reject streams. The purpose of this work is to introduce an MINLP able to optimize inter-plant water network with single-pass and partitioning regenerators, based on the total annualized cost. The model is capable of selecting the best regeneration option; single-pass or partitioning regenerator or both of them, which achieves the minimum total annualized cost. Lingo optimization program version 14 is used.

\section{Problem statement}

Given a set of single contaminant water networks (k); each water network has the following data:

- A set of process sources, $i=1,2, \ldots N_{\text {sources.; }}$ each source i, has a flowrate, $\operatorname{FSR}(i)$ of contaminant concentration, $\mathrm{C}_{\mathrm{SR}, \mathrm{i}}$.

- A set of process sinks, $\mathrm{j}=1,2, \ldots \mathrm{N}_{\text {sinks. }}$; each sink $\mathrm{j}$, has a flowrate $\operatorname{FSK}(j)$ with maximum contaminant concentration, $\mathrm{C}_{\mathrm{SK}, \mathrm{j}}$.

- Available also a fresh water source (FIPWI) that can be purchased to supplement process sinks requirements for the networks.

- There are centralized regenerators (single- pass with outlet concentration $\mathrm{C}_{\operatorname{mix}}$ and partitioning regenerators with top product concentration $C_{p}$ and bottom or reject product concentration $C_{R}$ ) between the water networks for regenerating the sources from each network. Two regenerators have been assumed in this work.

The objective of this paper is to synthesize an optimum indirect inter-plant water network and select the optimum regenerator(s), which achieve minimum total annualized cost. For indirect interplant integration, water networks are interconnected via centralized single-pass and partitioning regenerators. Hence, direct water integration between different networks is forbidden.

In the proposed model, the optimization program will decide if two regenerators, i.e. single-pass and partitioning regenerators or either of them are to be used to achieve the specified objective function. An optimization model for selecting optimum single-pass and partitioning regenerators of indirect inter-plant water integration is presented.

Figure (1) shows the superstructure for the indirect inter-plant water integration scheme with single-pass and partitioning regenerators.

\section{Mathematical model}

As showed in Figure (1), the cross-plant flowrate that is sent from source (i) to regenerator $m$ is known as the export flowrate (Fexport(i)regen, $\mathrm{m}$ ). The crossplant flowrate that is sent from the product stream $\mathrm{g}_{\mathrm{cpregen}, 1}$ of the single pass regenerator 1 to $\sin \mathrm{k} \mathrm{j}$ in the two networks is known as import flowrate (Fimport(j)regen,1) and the cross-plant flowrate that is sent from the top product stream of the partitioning regenerator 2 to sink $\mathrm{j}$ in the two networks is known as import top flowrate (FimportT(j)regen, 2) and the cross-plant flowrate that is sent from the bottom product stream of the partitioning regenerator 2 to sink $\mathrm{j}$ in the two networks is known as import bottom flowrate (FimportB(j)regen, 2). 


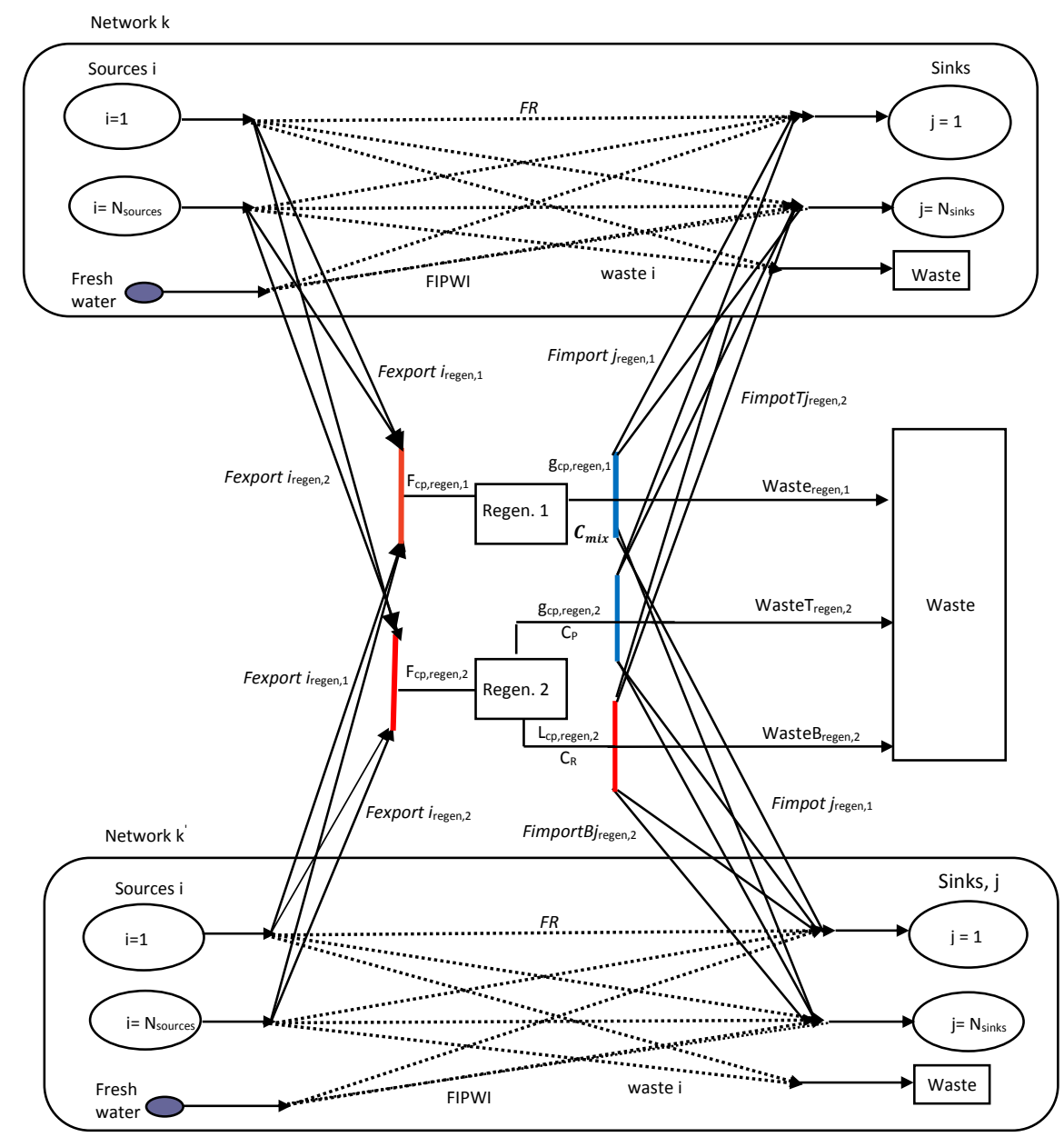

Figure 1 Superstructure for indirect inter plant water integration with single-pass and partitioning regenerators

In this model we let the optimization program decides if the two regenerators, single pass and partitioning regenerators or one of them give the minimum objective function.

The following set of equations represent the mathematical model, aiming to select the optimum regenerator(s) (single-pass and/or partitioning), which achieves the minimum objective function. The objective function applied in this work is the minimization of the total annualized cost as presented in Eq. (1).

$$
\begin{aligned}
\min =\left[\sum_{k \in K} F I P W I_{j, K} \cdot\right. & W_{\text {cost } j, k}+M_{\text {regen }} \cdot R_{\text {cost }}+F_{c p, \text { regen }, 2} \cdot Q_{\text {cost }} \\
& \left.+ \text { waste } \cdot U_{\text {cost }}\right] A W H \\
& +\left[\sum_{m \in M} \text { Pipe }_{\text {regen }, m}\right] A f \quad \forall j \epsilon J, \quad \forall k \epsilon K, \\
\forall m \epsilon M &
\end{aligned}
$$

Where: $F I P W I_{j K}$ : is the fresh IPWI for each sink $\mathrm{j}$ in each network $\mathrm{k}, W_{\text {cost } j, k}$ is the unit cost of each fresh water to the networks, and $A W H$ is the annual working hours per year, $M_{\text {regen }}$ : is the mass load removed for the first single pass regenerator and can be calculated by using Eq. (2), $R_{\text {cost }}$ is unit cost of mass load removed, $F_{c p \text {,regen, } 2}$ : is the regenerated flowrate to the partitioning regenerator, $Q_{\text {cost }}$ is unit cost of the regenerated flowrate, waste: is summation of wastewater from the two networks $\left(\sum_{i \in I}\right.$ waste $\left._{i}\right)$, the wastewater from regenerator 1

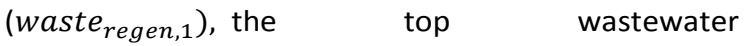
(waste $T_{\text {regen, } 2}$ ) and the bottom wastewater (waste $B_{\text {regen, } 2}$ ) from regenerator 2 as presented in Eq. (3), $U_{\text {cost }}$ is the unit cost of the treated wastewater flowrate. Pipe regen,m $_{\text {: }}$ is the pipelines capital cost between the sources of the networks and the regenerators and between the sinks of the networks and the regenerators. The pipelines capital cost can be calculated from Eq. (4). 


$$
\begin{aligned}
& M_{\text {regen }}=\sum_{i \in I} \text { Fexport }(i)_{\text {regen }, 1} C_{S R, i} \\
& \text { - }\left(\sum_{j \in J} \text { Fimport }(j)_{\text {regen }, 1}\right. \\
& \left.+ \text { waste }_{\text {regen }, 1}\right) \cdot C_{m i x} \\
& \text { waste }=\sum_{i \in I} \text { waste }_{i}+\text { waste }_{\text {regen }, 1}+\text { waste }_{\text {regen, } 2} \\
& + \text { wasteB }_{\text {regen, } 2} \\
& \text { Pipe }_{\text {regen,m }} \text { (US\$) } \\
& =\left[\left(250 \mathrm{X}_{\mathrm{INDIR}}(\mathrm{k})+7200 \frac{\mathrm{F}_{\mathrm{cp}}(\mathrm{k})_{\text {regen,m }}}{3600 . \rho . \mathrm{v}}\right)\right. \\
& +\left(250 \mathrm{Y}_{\mathrm{INDIR}}(\mathrm{k})+7200 \frac{\mathrm{g}_{\mathrm{cp}}(\mathrm{k})_{\mathrm{regen}, \mathrm{m}}}{3600 . \rho . \mathrm{v}}\right) \\
& \left.+\left(250 \mathrm{Z}_{\mathrm{INDIR}}(\mathrm{k})+7200 \frac{\mathrm{L}_{\mathrm{cp}}(\mathrm{k})_{\text {regen, } \mathrm{m}}}{3600 \cdot \rho \cdot \mathrm{v}}\right)\right] \text { Length } \quad \forall m \epsilon M
\end{aligned}
$$

Note that, the pipelines cost inside each network is neglected because their cost is very small when compared with the other pipelines cost Chew et al. [1].

The flowrate balance for a source FSR(i) and a sink FSK(j) are as described in Eqs. (5), (6).

$$
\begin{aligned}
F S R(i)=\sum_{j \epsilon J} F R(i, j) & +\sum_{i \epsilon I} F \text { export }(i)_{\text {regen }, 1}+ \\
\sum_{i \epsilon I} F \text { export }(i)_{\text {regen }, 2} & + \text { waste }(i) \quad \forall i \epsilon I, \quad \forall j \epsilon J \\
F S K(j)=\sum_{i \epsilon I} F R(i, j) & + \text { Fimport }(j)_{\text {regen }, 1} \\
& + \text { Fimport }(j)_{\text {regen }, 2} \\
& + \text { Fimport } B(j)_{\text {regen }, 2}+\text { FIPWI }(j)
\end{aligned}
$$

Where $F R(i, j)$ is reuse/recycle flowrate from source $\mathrm{i}$ to sink $\mathrm{j}$.

The impurity load constraint for the sink is presented in Eq. (7).

$\sum_{i \in I} F R(i, j) \cdot C_{S R, i}+$ Fimport $(j)_{\text {regen }, 1} \cdot C_{m i x}+$

FimportT $(j)_{\text {regen,2. }} \cdot C_{p}+$ Fimport $B(j)_{\text {regen }, 2} \cdot C_{R}+$ $F I P W I(j) \cdot X_{F} \leq F S K(j) \cdot C_{S K, j}$

There is not any direct cross pipeline flowrate from network $\mathrm{k}$ to the other network $\mathrm{k}^{\prime}$ as described in Eq. (8).

$\sum_{\mathrm{i} \in \mathrm{I}_{\mathrm{k}}} \sum_{\mathrm{j} \in \mathrm{J}_{\mathrm{k}}} F R(i, j)$

Flow balance for each regenerator is shown in the following set of equations: where Eqs. (9) to (13) for single pass regenerator and Eqs. (14) to (22) for partitioning regeneration system.

$F_{c p}(k)_{\text {regen }, 1}=\sum_{i \in I}$ Fexport $(i)_{\text {regen }, 1} \quad \forall i \epsilon I, \quad \forall k \epsilon K$
$g_{c p}(k)_{\text {regen }, 1}=\sum_{j \in J}$ Fimport $(j)_{\text {regen }, 1}$
$g_{c p_{\text {regen }, 1}}=\sum_{k \in K} g_{c p}(k)_{\text {regen }, 1}+$ waste $_{\text {regen }, 1}$

$$
\begin{aligned}
& \sum_{i \in I} \text { Fexport }(i)_{\text {regen }, 1}=\left[\sum_{j \in J} \text { Fimport }(j)_{\text {regen }, 1}+\right. \\
& \text { waste } \left._{\text {regen }, 1}\right] \quad \forall i \in I \text {, } \\
& \forall j \in J \\
& F_{c p, r e g e n, 1}=g_{c p, r e g e n, 1} \\
& F_{c p}(k)_{\text {regen }, 2}=\sum_{i \in I} \text { Fexport }(i)_{\text {regen }, 2} \\
& F_{c p_{\text {regen }, 2}}=\sum_{i \in I} F_{c p}(k)_{\text {regen }, 2} \quad \forall k \epsilon K \\
& g_{c p}(k)_{\text {regen }, 2}=\sum_{j \in J} \text { Fimport } T(j)_{\text {regen }, 2} \\
& g_{c p_{\text {regen }, 2}}=\sum_{k \in K} g_{c p}(k)_{\text {regen }, 2}+\text { wasteT }_{\text {regen }, 2} \\
& L_{c p}(k)_{\text {regen }, 2}=\sum_{j \in J} \text { Fimport } B(j)_{\text {regen }, 2} \\
& L_{c p_{\text {regen }, 2}}=\sum_{k \in K} L_{c p}(k)_{\text {regen }, 2}+\text { wasteB }_{\text {regen }, 2}
\end{aligned}
$$

$$
\begin{aligned}
\sum_{i \in I} \text { Fexport }(i)_{\text {regen }, 2} & =\left[\sum_{j \in J} \text { Fimport } T(j)_{\text {regen }, 2}\right. \\
& +\sum_{j \in J} \text { Fimport } B(j)_{\text {regen }, 2}+\text { waste }_{\text {regen }, 2} \\
& \left.+ \text { wasteB }_{\text {regen }, 2}\right]
\end{aligned}
$$

$\sum_{i \in I}$ Fexport $(i)_{\text {regen }, 2} \cdot C_{S R, i}=$

$\left[\sum_{j \in J}\right.$ FimportT $(j)_{\text {regen }, 2}+$ wasteT $\left._{\text {regen }, 2}\right] \cdot C_{P}+$

$\left[\sum_{j \in J}\right.$ FimportB $(j)_{\text {regen, }, 2}$ wasteB $\left._{\text {regen }, 2}\right] \cdot C_{R}$

$F_{c p, r e g e n, 2}=g_{c p, r e g e n, 2}+L_{c p, \text { regen }, 2}$

Eq. (23) indicates the upper and lower bounds of crossplant flowrates $F_{c p}(k)_{\text {regen,m}}$. The binary variable $\mathrm{X}_{\mathrm{INDIR}}(\mathrm{k})_{\text {regen,m }}$ indicates the existence of a crossplant pipeline from all sources of each network to regenerator $\mathrm{m}$.

$$
\begin{aligned}
\mathrm{LB}_{\mathrm{cp}} \cdot \mathrm{X}_{\mathrm{INDIR}}(\mathrm{k})_{\text {regen, } \mathrm{m}} & \leq \mathrm{F}_{\mathrm{cp}}(\mathrm{k})_{\text {regen, } \mathrm{m}} \\
& \leq \mathrm{UB}_{\mathrm{cp}} \cdot \mathrm{X}_{\mathrm{INDIR}}(\mathrm{k})_{\text {regen,m }} \quad \forall \mathrm{k} \in \mathrm{K}, \\
& \forall \mathrm{m} \in \mathrm{M}
\end{aligned}
$$

Eq. (24) represents the upper and lower bounds of cross-plant flowrates $\mathrm{g}_{\mathrm{cp}}(\mathrm{k})_{\text {regen,m; }}$ the binary variable $\mathrm{Y}_{\text {INDIR }}(\mathrm{k})_{\text {regen,m }}$ indicates the existence or absence of cross-plant flow from the top product of the regenerator to all sinks of network, $k$.

$\mathrm{LB}_{\mathrm{cp}} \cdot \mathrm{y}_{\text {INDIR }}(\mathrm{k})_{\text {regen, } \mathrm{m}} \leq \mathrm{g}_{\mathrm{cp}}(\mathrm{k})_{\text {regen,m }}$
$\leq \mathrm{UB}_{\mathrm{cp}} \cdot \mathrm{y}_{\text {INDIR }}(\mathrm{k})_{\text {regen,m }} \quad \forall \mathrm{k} \in \mathrm{K} \quad \forall \mathrm{m} \in \mathrm{M}$

Upper and lower bounds of cross-plant flowrates $\mathrm{L}_{\mathrm{cp}}(\mathrm{k})_{\text {regen,m }}$ are shown in Eq. (25). The binary variable $\mathrm{Z}_{\mathrm{INDIR}}(\mathrm{k})_{\text {regen,m }}$ indicates the existence or absence of cross-plant pipeline from the bottom product of the partitioning regenerator to all sinks of network k. Eq (26) indicates the limitation for the number of interconnections. 
$\mathrm{LB}_{\text {cp }} \mathrm{Z}_{\text {INDIR }}(\mathrm{k})_{\text {regen,m }} \leq \mathrm{L}_{\mathrm{cp}}(\mathrm{k})_{\text {regen, } \mathrm{m}}$

$\leq \mathrm{UB}_{\mathrm{cp}} \mathrm{Z}_{\text {INDIR }}(\mathrm{k})_{\text {regen,m }}$

$$
\begin{aligned}
\sum_{\mathrm{k} \in \mathrm{K}} \mathrm{X}_{\text {INDIR }}(\mathrm{k})_{\text {regen, } \mathrm{m}}+ & \sum_{\mathrm{k} \in \mathrm{K}} \mathrm{Y}_{\text {INDIR }}(\mathrm{k})_{\text {regen }, \mathrm{m}} \\
& +\sum_{\mathrm{k} \in \mathrm{K}} \mathrm{Z}_{\text {INDIR }}(\mathrm{k})_{\text {regen }, \mathrm{m}} \leq \mathrm{N}
\end{aligned}
$$

\section{Partitioning regeneration system with fixed outlet concentration (Fixed $\mathrm{C}_{\text {out }}$ )}

Lower and upper bounds of the bottom product concentration $\left(C_{R}\right)$ of regenerator 2 are included in the model as described in Eq. (27).

$\mathrm{C}_{\mathrm{R},}^{\min } \leq \mathrm{C}_{\mathrm{R},} \leq \mathrm{C}_{\mathrm{R}}^{\max }$

Where $C_{R}^{\min }$ and $C_{R}^{\max }$ are the minimum and maximum bottom concentration of all sources of the networks, when they are regenerated individually without indirect interplant water integration; they could be calculated using Eq. (28) [13].

$\mathrm{C}_{\mathrm{R}, \mathrm{i}}=\frac{\left[\mathrm{C}_{\mathrm{SRi}}-\frac{\left(10^{6}-\mathrm{C}_{\mathrm{SRi}}\right)}{\left(10^{6}-\mathrm{C}_{\mathrm{P}}\right)} \cdot \alpha_{1} \cdot \mathrm{C}_{\mathrm{P}}\right]}{\left[1-\frac{\left(10^{6}-\mathrm{C}_{\mathrm{SRi}}\right)}{\left(10^{6}-\mathrm{C}_{\mathrm{P}}\right)} \cdot \alpha_{1}\right]} \quad \forall i \epsilon I$

\section{Single- pass and partitioning}

\section{regenerator system with fixed removal}

\section{ratio (Fixed $\mathbf{R R}$ )}

For a single pass regenerator, the impurity balance is modified as described in Eq. (29).

$$
\begin{aligned}
& {\left[\sum_{\mathrm{j} \in \mathrm{J}} \text { Fimport }(\mathrm{j})_{\text {regen }, 1}+\text { waste }_{\text {regen }, 1}\right] \cdot \mathrm{C}_{\text {mix }} } \\
&=\sum_{\mathrm{i} \in \mathrm{I}} \text { Fexport }(\mathrm{i})_{\text {regen }, 1} \mathrm{C}_{\mathrm{SR}, \mathrm{i}} \cdot(1-\mathrm{RR})
\end{aligned}
$$

For partitioning regenerator, lower and upper bounds of the bottom product are as described in Eqs. (27) and (28). The upper and the lower bounds of the top product concentration $\left(\mathrm{C}_{\mathrm{P}}\right)$ of the partitioning regenerator are included in the model as described in Eqs. (30) and (31)

$$
\begin{aligned}
& \mathrm{C}_{\mathrm{P}}^{\min } \leq \mathrm{C}_{\mathrm{P}} \leq \mathrm{C}_{\mathrm{P}}^{\max } \quad \forall \mathrm{i} \in \mathrm{I} \\
& \mathrm{C}_{\mathrm{P}}=\frac{\left[\mathrm{C}_{\mathrm{SRi}} \cdot(1-\mathrm{RR}) \cdot 10^{6}\right]}{\left[\alpha_{\mathrm{l}}\left(10^{6}-\mathrm{C}_{\mathrm{SRi}}\right)+\mathrm{C}_{\mathrm{SRi}} \cdot(1-\mathrm{RR})\right]} \quad \forall \mathrm{i} \in \mathrm{I}
\end{aligned}
$$

\section{Case studies}

Two case studies are solved to illustrate the indirect IPWI for selection between single-pass and partitioning regenerators for Indirect IPWI by the proposed model when the regenerators are with fixed outlet concentration (Fixed-Cout) and with fixed removal ratio (fixed-RR).

\section{Case study 1 (Using regenerators with fixed outlet concentration)}

This case study involves two water networks taken from Chew et al. [1]. The limiting water data for the two networks are tabulated in Table (1). For the two networks, zero contaminant fresh water sources are assumed. In addition, the following key assumptions are introduced:

- There is a single pass regeneration unit 1 of fixed outlet concentration (Cmix $=50 \mathrm{ppm})$ with cost $\left(\mathrm{R}_{\text {cost }}\right) 0.01 \$ / \mathrm{kg}$ of impurity mass load removed

- $\quad$ Equal distance of length $=300 \mathrm{~m}$ between all water networks and the regenerators. The capital cost for the cross-plant pipelines was annualised to a period of 5 years with a fixed rate of interest $5 \%$. This leads to an $A f$ of 0.231 .

- The stream velocity is assumed as $1 \mathrm{~m} / \mathrm{s}$ and water density as $1,000 \mathrm{~kg} / \mathrm{m} 3$. AWH is assumed to be $8,000 \mathrm{~h} / \mathrm{y}$.

- Unit cost for fresh water is assumed to be $\$ 1 / \mathrm{t}$ for the two networks and unit cost of wastewater treatment is $\$ 1 / \mathrm{t}$.

- Partitioning regeneration unit 2 of fixed outlet concentration $(\mathrm{Cp}=50 \mathrm{ppm})$ with cost $\left(Q_{\text {cost }}\right) 0.5 \$ / t$.

- The fluid flow recovery $\left(\alpha_{1}\right)$ is taken as $70 \%$ It is required to synthesize indirect inter plant water integration for the two networks.

The lower and upper bounds of the bottom product concentrations for the second regenerator (partitioning regenerator) are calculated using Eq. (28). The lower and upper bounds are 149.993 and 3209.662 .

Solving Eq. (1) subjected to the constraints Eqs. (2) to (26) and (28) the results of the optimization showed that: single pass regenerator 1 is the only optimum regenerator for this case study giving the minimum objective function. The fresh water is $40 \mathrm{t} / \mathrm{h}$ and the wastewater is $40 \mathrm{t} / \mathrm{h}$. The minimum objective 
function is $\$ 713,578.6$ per year. The optimum design of theThe previous case study has been resolved assuming two networks is showed in Figure 2. the regenerator's removal ratio is fixed. It is assumed

Table 1 Limiting data for two water networks in case study

\begin{tabular}{|c|c|c|c|c|c|c|}
\hline Network 1 & $\begin{array}{l}\text { Water } \\
\text { sources }\end{array}$ & $\begin{array}{l}\text { Flowrates } \\
\qquad(\mathrm{t} / \mathrm{h})\end{array}$ & $\begin{array}{c}\text { Impurity } \\
\text { Concentration } \\
\text { (PPM) }\end{array}$ & $\begin{array}{l}\text { Water } \\
\text { sinks }\end{array}$ & $\begin{array}{c}\text { Flowrates } \\
(\mathrm{t} / \mathrm{h})\end{array}$ & $\begin{array}{c}\text { Impurity } \\
\text { Concentration } \\
\text { (PPM) }\end{array}$ \\
\hline & FSR1 & 66.67 & 80 & FSK1 & 20 & 0.0 \\
\hline & FSR2 & 20 & 100 & FSK2 & 66.67 & 50 \\
\hline & FSR3 & 100 & 100 & FSK3 & 100 & 50 \\
\hline & FSR4 & 41.67 & 800 & FSK4 & 41.67 & 80 \\
\hline & FSR5 & 10 & 800 & FSK5 & 10 & 400 \\
\hline Fresh & \multicolumn{5}{|c|}{ To be determined } & 0.0 \\
\hline Network 2 & $\begin{array}{l}\text { Water } \\
\text { sources }\end{array}$ & $\begin{array}{l}\text { Flowrates } \\
\qquad(\mathrm{t} / \mathrm{h})\end{array}$ & $\begin{array}{c}\text { Impurity } \\
\text { Concentration } \\
\text { (PPM) }\end{array}$ & $\begin{array}{l}\text { Water } \\
\text { sinks }\end{array}$ & $\begin{array}{c}\text { Flowrates } \\
(\mathrm{t} / \mathrm{h})\end{array}$ & $\begin{array}{c}\text { Impurity } \\
\text { Concentration } \\
\text { (PPM) }\end{array}$ \\
\hline & FSR1 & 66.67 & 80 & FSK1 & 20 & 0.0 \\
\hline & FSR2 & 20 & 100 & FSK2 & 66.67 & 50 \\
\hline & FSR3 & 15.63 & 400 & FSK3 & 15.63 & 80 \\
\hline & FSR4 & 42.86 & 800 & FSK4 & 42.86 & 100 \\
\hline & FSR5 & 6.67 & 1000 & FSK5 & 6.67 & 400 \\
\hline Fresh & \multicolumn{5}{|c|}{ To be determined } & 0.0 \\
\hline
\end{tabular}

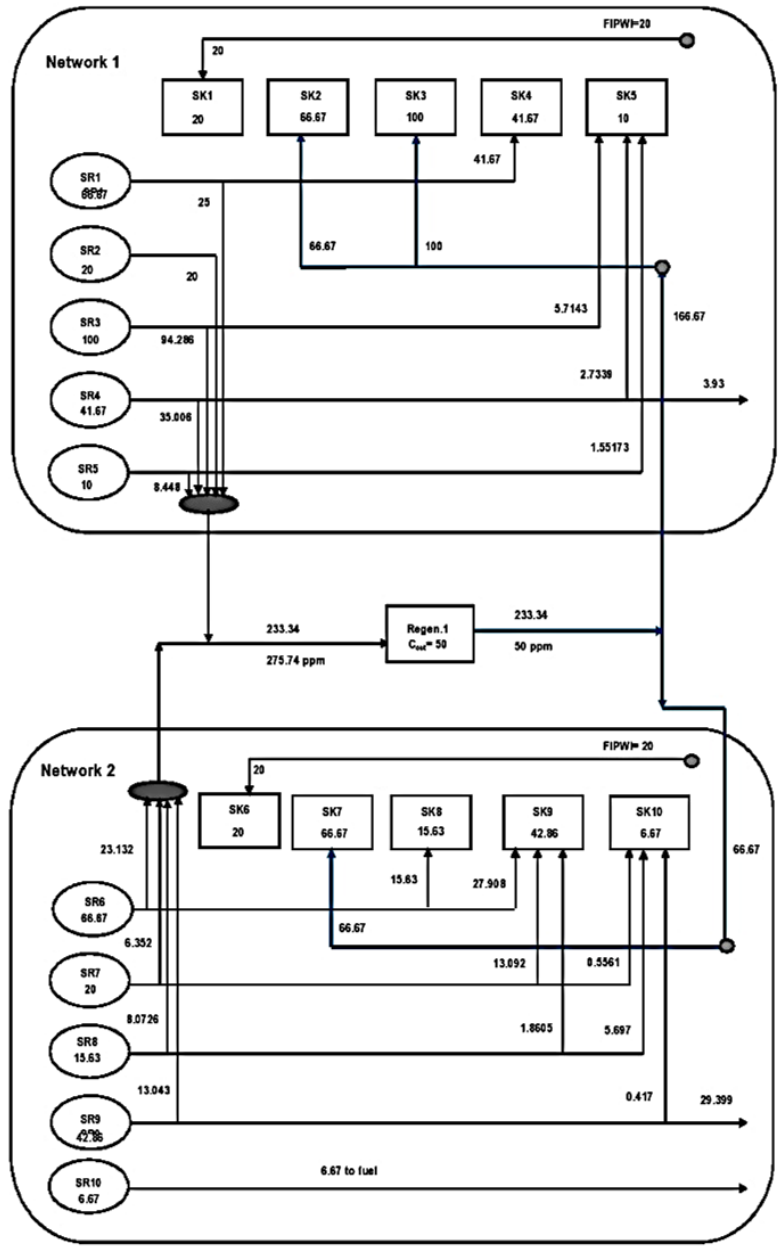

Figure 2 Optimized Indirect IPWI design for case study 1 (Fixed $\mathrm{C}_{\text {out }}$ )

\section{Case study 2 (Using regenerators with fixed removal ratio)}

that the single pass regeneration unit 1 has fixed removal ratio as $80 \%$, with cost $\left(\mathrm{R}_{\text {cost }}\right) \$ 2.06 / \mathrm{kg}$ while partitioning regeneration unit 2 has fixed removal ratio as $90 \%$ with cost $\left(Q_{\text {cost }}\right) \$ 0.3 / t$. The fluid flow recovery $\left(\alpha_{1}\right)$ of $98 \%$ is also suggested.

For regenerator 1 , the outlet concentration $\left(C_{\text {mix }}\right)$ is unknown but the removal ratio is known. For regenerator 2, using Eq. (27) and (28) for the lower and upper bound of the bottom product concentration and Eq. (30) and (31) for the lower and upper bound of the top product concentration.

The lower and upper bound of the bottom product concentration are 8.1639 and 102.1325 PPM.

The lower and upper bound of the bottom product concentration are 3587.37 and 43103.4495 PPM Solving equation 1 subjected to the constraints Eqs. (2) to (31) the optimal results have been achieved.

The two regenerators together give the minimum total annual cost as $\$ 980,489.9 / y$. The minimum freshwater requirement is $40 \mathrm{t} / \mathrm{h}$ and the wastewater discharge is $40 \mathrm{t} / \mathrm{h}$. Each network has the same amount of freshwater $(20 \mathrm{t} / \mathrm{h})$. The regenerated water sent to single-pass and partitioning regenerators has flowrates 61.0867 , and $64.9868 \mathrm{t} / \mathrm{h}$, respectively.

It is noted that, the Lingo optimization program chooses the partitioning regenerator only when the 
number of the cross-plant pipelines $(\mathrm{N})$ is decreased to 4 but with higher annualized cost. The optimum design of the two networks is shown in Figure 3, with 6 cross-plant pipelines.

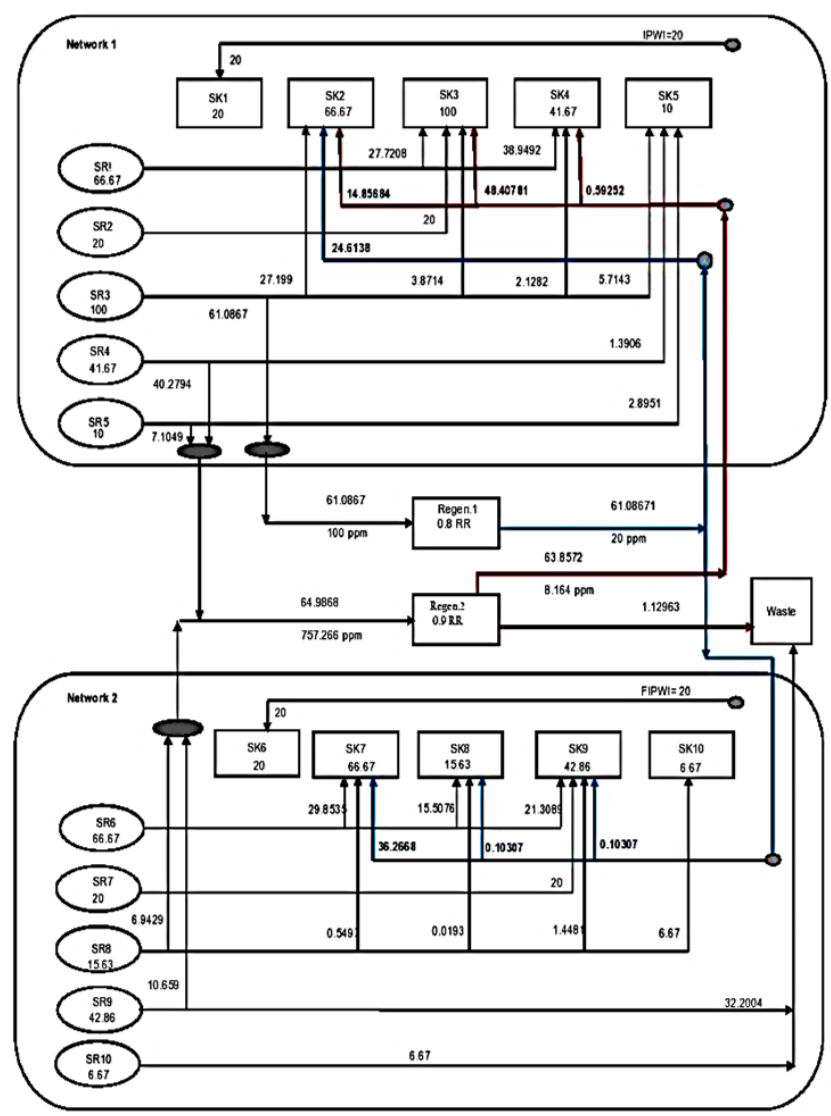

Figure 3 Optimized Indirect IPWI design for case study 1 (Fixed Removal Ratio)

\section{Conclusion}

In this work, a superstructure model is proposed for indirect inter-plant water integration. The model is developed for regeneration systems with fixed outlet concentration and fixed removal ratio. A mathematical model is introduced in order to select the optimum regenerator(s) (single-pass, partitioning regenerator, or both) which achieve the minimum total annualized cost for inter-plant water integration. Two case studies have been introduced to demonstrate the effectiveness of the presented model. For case study 1 with fixed outlet concentration, one single-pass regenerator has achieved the minimum annualized cost. For case study 2 with fixed removal ratio, two regenerators, single-pass and partitioning are required to achieve the minimum annualized cost. The model can solve the inter-plant system effectively by selecting the required regenerators achieving the minimum total annualized cost.

\section{Nomenclature}

$A W H$ : Annual working hours per year

$\mathrm{C}_{\mathrm{B}, \mathrm{m}}^{\min }$ and $\mathrm{C}_{\mathrm{B}, \mathrm{m}}^{\max }$ : minimum and the maximum bottom concentration of all sources of the networks

$\mathrm{C}_{\text {mix }}$ : Outlet concentration of single pass regenerator

$C_{P}$ : Concentration of the top product stream of the partitioning regenerator

$C_{R}$ : Concentration of the bottom product stream of the partitioning regenerator

$C_{S K, j}$ : Maximum contaminant concentration of sink (j)

$C_{S R, i}$ : Contaminant concentration of source (i)

$\mathrm{F}_{\mathrm{cp}}(\mathrm{k})_{\text {regen,m}}$ : Regenerated flowrate sent from network $\mathrm{k}$ to regenerator $\mathrm{m}$

$F_{c p}$, regen, $m$ :Input flowrate for regenerator $\mathrm{m}$

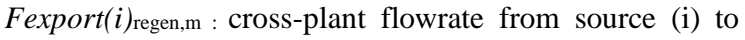
regenerator $\mathrm{m}$

FimportB $(j)_{\text {regen,m: }}$ cross-plant flowrate from the bottom product stream of regenerator $m$ sent to sink $\mathrm{j}$ in the two networks

Fimport $\mathrm{T}(\mathrm{j})_{\text {regen,m: }}$ cross-plant flowrate from the top product stream of regenerator $m$ sent to sink $j$ in the two

$F I P W I_{j K}$ : inter plant water fresh flowrate for each sink $\mathrm{j}$ in each network $\mathrm{k}$

FSK(j): Flowrate of sink (j)

FR(i,j) : Reuse/recycle flowrate from source i to sink j.

$g_{c p}($ regen, $m):$ Total top output of regenerator $\mathrm{m}$

$\mathrm{K}$ : number of networks

$\mathrm{LB}_{\mathrm{cp}}$ : Lower bound of flow for regenerator $\mathrm{m}$

$L_{c p}(k)_{\text {regen, } m}$ : Portion of bottom product of regenerator $\mathrm{m}$ sent to network k

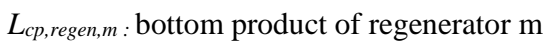

M: number of regenerators

$M_{\text {regen }}$ : The mass load removed for first single pass regenerator

Pipe $_{\text {regen }, m}$ : Pipeline cost

$Q_{\text {cost }}$ : Regeneration unit cost of the second regenerated

$R_{\text {cost }}$ : Unit cost of mass load removed

RR: removal ratio

$U_{\text {cost }}:$ Unit cost for wastewater treatment

$\mathrm{UP}_{\mathrm{cp}}$ : Upper bound of flow for regenerator $\mathrm{m}$

$W_{\text {costj,k }}:$ Unit cost of fresh water to the networks

$\mathrm{X}_{\text {INDIR }}(\mathrm{k})_{\text {regen,m}}$ : Binary variable indicates the existence of cross-plant pipeline from all sources of each network to regenerator $\mathrm{m}$.

$\mathrm{Y}_{\text {INDIR }}(\mathrm{k})_{\text {regen,m}}$ : Binary variable indicates the existence of cross-plant flow from the top product of the regenerator to all sinks of network $\mathrm{k}$. 
$\mathrm{Y}_{\text {INDIR }}(\mathrm{k})_{\text {regen,m}}$ : Binary variable indicates the existence of cross-plant flow from the top product of the regenerator to all sinks of network $\mathrm{k}$.

$\alpha$ : fluid recovery

\section{Funding sources}

This research received no external funding.

\section{Conflicts of interest}

There are no conflicts to declare.

\section{References}

[1] Chew I. M. L, Tan R, Ng D. K. S., Foo D. C. Y., Majozi T., Gouws J., 2008, Synthesis of Direct and Indirect Interplant Water Network, Industrial and Engineering Chemistry Research, 47, 9485-9496.

[2] Alnouri S., Stijepovic M., Linke P., El-Halwagi M., 2014, Optimal Design of Spatially Constrained Interplant Water Networks with Direct Recycling Techniques using Genetic Algorithms, Chemical Engineering Transactions, 39, 457-462.

[3] Garcia D.J., You F., 2015, Optimising the Water-Energy Nexus over Process and Product Networks, Chemical Engineering Transactions, 45, 391-396.

[4] Liu, L., Wang, J., Song, H., Du ,J., Yang, F., 2016, Synthesis of Water Networks for Industrial Parks Considering Inter-Plant Allocation, Computers and Chemical Engineering, 91, 307-317.

[5] Alnouri, S. Y., Linke, P., El-Halwagi, M. M., 2016, Synthesis of Industrial Park Water Reuse Networks Considering Treatment Systems and Merged Connectivity Options, Computers and Chemical Engineering, 91, 289-306.

[6] Liu, L., Wang, J., Song, H., Du, J., Yang, F., 2017, Multi-Period Water Network Management for Industrial Parks Considering Predictable Variations, Computers and Chemical Engineering, 104, 172-184.
[7] Li Y., 2018, Design of Water-using Network with Single Internal Water Main for Process Plants, Chemical Engineering Transactions, 65, 769-774.

[8] Aziz E.A., Hashim H., 2019, Integrated Optimisation of Energy-Water Nexus for Industrial Site Planning, Chemical Engineering Transactions, 72, 307-312.

[9] Chew I. M. L., Foo D. C. Y, 2009, Automated targeting for inter-plant water integration, Chemical Engineering, 153, 23-36

[10] Chew I. M. L. Thillaivarrna S. L., Tan R. R., Foo D. C. Y., Analysis of inter-plant water integration with indirect integration schemes through game theory approach: Pareto optimal solution with interventions, Clean Technologies and Environmental Policy, 13, 4962

[11] Fan X.-Y., Li A.-H., Klemeš J. J., Liu Z.-Y., 2018, Advances in designing and targeting of water systems involving regeneration/treatment units, Journal of Cleaner Production, 197, part1, 1394-1407

[12] Deng C., Shi C., Feng X., Foo D. C. Y., 2016, Flowrate Targeting for Concentration- and Propertybased Total Water Network with Multiple Partitioning Interception Units, Industrial and Engineering Chemistry Research, 55, 7, 1965-1979

[13] Fonseca, A., Sa, V., Bento, H., Tavares, M. L.C., Pinto, G., Gomes, L.A.C.N., 2008, Hydrogen Distribution Network Optimization: a Refinery Case Study, Journal of Cleaner Production, 16, 1755-1763. 